\title{
NECROPODER, MUNDOS DE MORTE E MERCADO
}

\author{
NECROPOLITICS, DEATH-WORLDS AND MARKET \\ Renato Noguera'
}

\section{RESUMO}

A partir de uma afirmação feita por Achille Mbembe no ensaio Necropolítica, situando a Palestina como o exemplo mais bem organizado do necropoder, nós vamos analisar o seu duplo opositor, o Estado de Israel enquanto projeto filosófico-político da Terra prometida. O pano de fundo implícito de sustentação teórica de um dos conceitos mais célebres da filosofia mbembeana, a necropolítica, está nas contribuições decisivas da tese de Frantz Fanon presente nos Condenados da Terra. O objetivo é investigar como os processos de colonização estão assentados sob uma fantasia responsável pelo surgimento da raça, analisando sua conexão com o capitalismo neoliberal e, em paralelo, como o estabelecimento de uma tribo eleita com direito natural de habitar a Terra prometida vincula-se ao exercício de necropoder.

Palavras-chave: Necropoder; Mundos de morte; Mercado.

\section{ABSTRACT}

Based on a statement made by Achille Mbembe in the essay Necropolitics, placing Palestine as the best organized example of necropower, we will analyse its double opponent, the State of Israel as a philosophical-political project of the Promised Land. The implicit background of theoretical support of one of the most famous concepts of the Mbembean philosophy, the necropolitics, is in the decisive contributions of Frantz Fanon's thesis present in the The Wretched of the Earth. The objective is to investigate how colonization processes are based on a fantasy responsible for the emergence of race, analysing its connection with neoliberal capitalism and, in parallel, how the establishment of an elected tribe with natural right to inhabit the Promised Land is linked to necropower exercise.

Keywords: Necropower; Worlds of Death; Market.

\footnotetext{
1 Doutor em Filosofia pela Universidade Federal do Rio de Janeiro, professor do Programa de Pós-Graduação em Educação, Contextos Contemporâneos e Demandas Populares, do Programa de Pós-Graduação em Filosofia e do Departamento de Educação e Sociedade da Universidade Federal Rural do Rio de Janeiro. ORCID: http://orcid.org/0000-0002-6609-9360 E-mail: renatonoguera@ymail.com
} 


\section{INTRODUÇÃo}

Num exercício filosófico, o que uma breve introdução precisa nos dizer? O que está em jogo num exercício crítico filosófico? Ora, "não redizer o que disse um filósofo, mas dizer o que ele necessariamente subentendia, o que ele não dizia e que, no entanto, está presente naquilo que diz" (DELEUZE, 1996, p. 118). Portanto, aqui não se trata somente de apresentar a descrição do filósofo Achille Mbembe sobre necropolítica, mas "o que", "com" e "a partir" da necropolítica (esteja explícito ou não no ensaio de Mbembe). Aqui o que nos interessa é enfrentar o desafio de saber se somos capazes de pensar para encontrar caminhos possíveis para resistir ao mundo de morte.

O que Achille Mbembe pensa ou o que podemos pensar sobre o seu pensamento, mas "o que", "com" e "a partir" de Mbembe (seja em favor ou contra)? Somos (ainda) capazes de pensar sobre a contemporaneidade? O que Mbembe nos inspira a pensar a respeito da instalação do necropoder e dos caminhos possíveis para enfrentá-lo?

\section{O PRINCÍPIO FILOSÓFICO-TEOLÓGICO DO NECROPODER}

No final do livro Necropolítica, Achille Mbembe afirma: "A forma mais bem sucedida de necropoder é a ocupação colonial contemporânea da Palestina" (MBEMBE, 2015, p. 136). O que o filósofo camaronês propõe é mais do que uma imagem, mesmo que o texto não esteja suficientemente articulado para sustentar essa afirmação numa longa cadeia argumentativa. Sem dúvida, essa é a metáfora fundamental para a compreensão do necropoder como uma perspectiva ligada a uma disputa geopolítica com fundamentação étnico-religiosa. É preciso recuar, brevemente, no tempo para situar alguns aspectos da ideologia da tribo eleita que remontaria, eis a hipótese religiosa, o pacto divino do Deus de Israel com a humanidade. Como podemos interpretar essa narrativa cultural, segundo a qual um povo foi eleito por Deus para aproximá-lo do mundo, com o processo geopolítico do estabelecimento do Estado de Israel? No final do século XIX, os movimentos nacionalistas cresciam na Europa. Diante da diáspora judaica, Theodor Herzl defende a manutenção da identidade étnico-cultural do povo judeu através de um Estado independente.

\footnotetext{
Em maio de 1895, deu Herzl seu primeiro passo na rota do sionismo. Consistiu numa carta dirigida a um, então, muito conhecido filantropo judeu bávaro, o barão Maurice de Hirsch. Era este fundador da Jewish Colonization Association, organização que teve inicialmente por objetivo principal estabelecer judeus russos na Argentina e outras partes da América (isso porque o barão Hirsch queria afastá-los o mais possível da Rússia czarista) para que ali se dedicassem a trabalhos agrícolas. Nessa carta, pedia Herzl uma entrevista a fim de discutir "um plano político judaico cujos efeitos talvez se prolonguem a dias em que nem o senhor nem eu estaremos mais aqui". (LISSOVSKY, 2000, p. 55).
}

De acordo com o filósofo israelense Yehezkel Kaufmann (1989), Abraão é o fundador da religião monoteísta num elo direto com Adão. A religião de Israel: do início ao exílio babilônico é uma obra que aponta um povo escolhido por Deus para combater a idolatria e instituir os caminhos espirituais da humanidade. Para articular nossa hipótese, a tese de Kaufmann pode ser resumida como: o monoteísmo 
de Israel é inédito. Neste percurso de Abraão até Moisés, passando pelos patriarcas Isaac e Jacó, fica estabelecido como projeto geopolítico da Torá "a ocupação da Terra prometida por Deus, onde o povo de Israel poderá se dedicar a seu culto" (SORJ, 2014, p. 59). A partir das considerações de Kaufmann e Sorj, os descendentes do povo de Abraão têm um direito estabelecido por uma aliança espiritual com Deus; nós estamos diante da ideia de que Israel deve ser "uma luz entre". Vale repetir a nossa aposta, trata-se de um aspecto étnico-cultural que não pode ser desprezado na fundamentação do necropoder. A afirmação mbembeana da ocupação da Palestina como modelo-padrão de funcionamento da tecnologia necropolítica só faz sentido se atentarmos para essa perspectiva de que existe um povo eleito para aproximar o mundo de Deus. O necropoder tem base religiosa, o que dá os contornos basilares de seu caráter político. Não se trata de analisarmos o mundo judaico: as breves considerações servem para sustentar que a disputa de ocupação geopolítica e a tecnologia de morte têm um princípio etnocêntrico. Daí, por conta de um desígnio divino, isto é, um a priori - aqui entendido como um axioma ontológico-político -, alguns têm direito de reivindicar a posse da terra. Ora, esse princípio foi apropriado pelo colonialismo: toda terra estrangeira poderia ser ocupada em função de que o povo que invade estaria fazendo a vontade divina.

Barão Hirsch discordava de Herzl, o judeu austro-húngaro fundador do sionismo. "O que é, em essência, o sionismo? Responde Ben-Gurion: Sionismo significa o retorno a Sião" (SORJ, 2014, p. 18). A localização de "Sião", a terra prometida, foi alvo de debate, passando por conjecturas que pensavam em regiões da Europa, África e Ásia para estabelecer Israel, mas a preferência foi para o território onde ficava o Império Otomano. Após a $2^{\text {a }}$ Guerra Mundial, o Reino Unido tornou-se mandatário da região e em 1948 articulou a criação do Estado de Israel, o que está na base dos conflitos mencionados por Mbembe em Necropolítica.

Pois bem, considerando a afirmação que desencadeia nossa reflexão, podemos dizer hipoteticamente que só existe necropoder, porque temos um povo judeu que durante um processo histórico e político (re)estabeleceu a sua terra prometida, fundando o Estado de Israel. É preciso problematizar a expressão de "povo judeu", para isso vale destacar o trabalho do historiador israelense Shlomo Sand intitulado A invenção da terra de Israel: da terra santa à terra prometida (2014). De acordo com Sand, povo judeu faz tanto sentido, quanto afirmar a existência de um povo budista. Em outras palavras, não existe uma origem comum que possa remeter à "nação" ou a um projeto fundamental para toda a humanidade. Deste modo, o que temos é uma inevitável concepção racista construída em cima da percepção mítica dos judeus. Ora, se o racismo está em cena, encontramos um elemento decisivo para compreensão da Palestina como exemplo do exercício necropolítico. A narrativa de um povo que tinha um reino, tornou-se errante e depois voltou ao seu lugar de "direito" só pode ser construída numa ideologia essencialista que qualifica um povo a tomar algo que naturalmente é seu, o que pode ser feito em última instância por todos os meios.

\section{O TERROR COLONIAL}

Sem dúvida, Mbembe é leitor de Hannah Arendt e Michel Foucault e dialoga com essa dupla filosófica para confeccionar sua Necropolítica. Porém, interessa-nos aqui mais ainda sua conversa com Frantz Fanon, porque a formulação necropolítica de Mbembe está muito mais próxima das reflexões fanonianas 
sobre a violência colonial do que da biopolítica foucaultiana. O que, longe de negar a proximidade e influência entre os pensamentos de Foucault e Mbembe, significa que devemos sublinhar uma peculiaridade incontornável. O risco de morte é permanente na colônia, o que contribui para explicar bem a gênese das práticas necropolíticas no contexto do neoliberalismo. O que difere da análise foucaultiana. Por isso, as interpretações de que a necropolítica seria uma reedição da biopolítica de Foucault são equívocas. Essa impressão ocorre justamente porque algumas leituras de Foucault e de Mbembe, mesmo que bem-feitas, para compreender o fenômeno do necropoder carecem de um mergulho nos escritos de Fanon. Foucault trata do Estado nazista alemão. Vale a pena dizer que foi estabelecido um tribunal para julgar os crimes de guerra contra a humanidade, de novembro de 1945 a outubro de 1946, por 315 dias no Palácio de Nuremberg na Alemanha (1949).

Mas, o que dizer de escravagistas eurodescendentes na América? O que dizer das companhias de navios negreiros que faziam tráfico internacional de pessoas? Sem dúvida, é uma resposta intelectualmente plausível, supor esse julgamento retroativo seria um anacronismo histórico. Do ponto de vista formal, o Estado nazista foi combatido por outras nações. Porém, o colonialismo era um consenso do mundo ocidental moderno e uma das ferramentas-chave era a violência.

Em Escritos políticos, encontramos que a estrutura da lógica colonial está expressa na violência como linguagem. "Eles nos montam como autômatos e nos soltam em cima de populações que nos fizeram', dizia Vitorio Fantini. E acrescentava que essa técnica de embrutecimento era amplamente facilitada pelo próprio ambiente em que seus colegas e ele viviam" (FANON, 2021). Fantini é um boxeador italiano que foi preso na cidade de Metz em fevereiro de 1957, o motivo: irregularidades referentes a seu passaporte. Então, ele teve duas opções, seguir em cárcere ou prestar cinco anos de serviços defendendo a bandeira da França. A Legião Estrangeira reúne desde sua fundação, em 1831, soldados de diferentes nacionalidades para lutar em prol da sua agenda colonial. Em Escritos políticos, Fanon se refere ao processo de doutrinação que legionários franceses contrarrevolucionários recebiam do Estado francês para reprimir a resistência argelina na década de 1950. Tal como diz Fantini, se trata de um processo de "sensibilização negativa", transformando o soldado insensível para a humanidade das pessoas colonizadas. Diante desse processo sistemático de insensibilização dos sujeitos da metrópole para que a morte dos "selvagens" seja algo fácil de realizar, convidamos para a leitura de dois trechos de Necropolítica para argumentar que o terror na Colônia não tinha precedentes na Metrópole.

Na realidade, as ligações entre a modernidade e o terror provêm de várias fontes. Algumas são identificáveis nas práticas políticas do Antigo Regime. A partir dessa perspectiva, a tensão entre a paixão do público por sangue e as noções de justiça e vingança são críticas. Foucault demonstra em Vigiar e punir como a execução do quase regicida Damiens durou horas, muito para a satisfação do público. (MBEMBE, 2015, p. 129).

O outro trecho na mesma página diz: "Não obstante, em nenhum momento se manifestou tão claramente a fusão da razão com o terror como durante a Revolução Francesa. Nesse período, o terror é interpretado como uma parte quase necessária da política" (MBEMBE, 2015, p. 129). Pois bem, Damiens era regicida, cometeu um crime e, como Foucault argumentou: a punição tinha que ser exemplar e se 
transformou, ao mesmo tempo, num espetáculo. No contexto do colonialismo, Fanon tem algo a dizer que pode ser bastante aproveitado: a violência na colônia é desmedida e não se faz contra criminosos, mas todos são, de antemão, condenados da terra (FANON, 2015). Um tipo de crime ontológico que é não ser nativo da metrópole europeia; povos originários da América e africanos estavam sob o terror somente por não serem gente branca. Do mesmo modo, não podemos deixar de registrar que o holocausto, que matou um povo em massa, foi aplicado na África, atingiu os povos Herero e Namaqua. Se o filósofo Theodor Adorno pergunta: "Como é possível educar após Auschiwtz?", nós não podemos deixar de dizer: "Como é possível a educação após Swakopmund?". A Alemanha de 1904 a 1907 impetrou um genocídio que só foi reconhecido em 1921 (ZANINI, 2021, p. A19). O terror colonial era uma prática numa terra previamente condenada, não se tratava de assassinar criminosos e dissidentes do regime como nas metrópoles europeias. A historiografia é rica em como desde as primeiras invasões europeias na África, na América e na Ásia, os assassinatos não passam por um julgamento. Os relatos de Foucault comentados por Mbembe tratam do poder soberano de júris, que aplicavam as leis aos infratores. No contexto colonial, todo colonizado era um infrator.

Nos primórdios do capitalismo, a colonização operava uma espécie de transferência das tensões irreconciliáveis do sistema liberal para um terreno no qual estavam instalados um tipo de "vale-tudo". Se um branco europeu assassinasse uma pessoa africana ou indígena do continente americano, não havia nenhuma punição. Isso não encontrava equivalência na metrópole. Os escravagistas brancos podiam dispor de uma pessoa escravizada como se fosse uma ferramenta de trabalho, a substituindo sempre que fosse necessário por outra "peça". A condição de mercadoria já ensejava as bases para instalação do necropoder.

O conceito de necropoder ganha mais força se estiver associado às reflexões de Fanon, o que não torna Foucault menos importante. No entanto, o filósofo francês está tratando do contexto europeu, porque uma perspectiva mais cuidadosa da tecnologia necropolítica não pode ficar restrita às metrópoles. O projeto de acumulação do capital para fortalecimento das nações escravagistas europeias modernas precisava estabelecer, de alguma forma, o direito de matar sem prejuízo para exploração das atividades econômicas. No mesmo período em que a revolução francesa era palco de violência brutal, o que estava acontecendo na América, na Ásia, África e na Oceania? Quanto tempo durou o terror dessa revolução? Por volta de uma década. Quanto tempo duraram invasões, ataques, escravização e exploração de europeus nos demais continentes? Daí, parafraseando Mbembe, "em nenhum momento se manifestou tão claramente a fusão da razão com o terror como durante os massacres aos povos originários da América e a escravização negra, em que a tortura e o assassinato eram regras institucionalizadas".

\section{O NEOLIBERALISMO E A TRIBO ELEITA}

O processo de violência colonial não cessou, foi adaptado e o esquema necropolítico foi se consolidando rapidamente em diversas sociedades multirraciais. Durante a forja da etapa neoliberal do capitalismo, a necropolítica passou a se tornar um tipo de tecnologia indispensável para manutenção da gestão domesticada das tensões raciais, de gênero e lutas de classe.

No contexto do neoliberalismo, a ideologia da tribo eleita é adaptada para ampliar os mecanismos de opressão e exploração ao máximo. Primeiro, brevemente por ideologia da tribo eleita devemos entender uma 
fixação etnocêntrica de que existe um povo designado a "cuidar" do mundo, ainda que isso signifique escravizar e explorar. Em segundo lugar, o neoliberalismo enquanto uma dimensão político-econômica e, ao mesmo tempo, filosófica e metapsicológica. Em seu primeiro aspecto, o neoliberalismo é um movimento político que faz parte do sistema capitalista instituído nos anos 1980 pelo Consenso de Washington $^{2}$ para responder desafios do esforço avaliado como malsucedido por uma condução da economia de mercado de modo heterodoxo realizada parcialmente ou totalmente por governos conservadores ou social-democratas, respectivamente (NOTERMANS, 2000; RODRIK, 2006). Por outro lado, neoliberalismo tem sentidos ontológico e psicológico que recobrem o sujeito como coisa, isto é, uma ferramenta de trabalho do capital motivada pelo autoengano de ser pessoa empreendedora de si mesma, e aprisionada aos seus próprios desejos. Daí, toda satisfação, alegria e felicidade ficam restritas à "capacidade de reconstruir publicamente sua vida íntima e de oferecê-la no mercado como uma mercadoria passível de troca" (MBEMBE, 2018, p. 16). A condição humana precisa ser instrumentalizável para que faça sentido. A partir das conjecturas de Sand de que o sionismo está enredado de racismo. E, por outro lado, a geração de inúmeros conflitos que se desenrolaram desde que o Estado de Israel foi estabelecido em 1948, transformando árabes, muçulmanos e outros grupos não-judeus em adversários políticos e inimigos internos. Neste contexto, matar o inimigo do Estado é indispensável. De algum modo, quem não produz é inimigo, a mesma noção de "vagabundo", um personagem rival das "pessoas de bem" que trabalham. Classificando, desta forma, os povos indígenas, quilombolas e tradicionais, que se relacionam com o trabalho de uma maneira não-capitalística, ou seja, vagabundo é aquele que executa um trabalho que não é explorado e não é produzido para acumulação, mas uma atividade para manutenção da vida.

Na conjuntura capitalística neoliberal, o discurso é de que precisamos nos capacitar bastante para ter um lugar no mundo do trabalho, inclusive, nos esforçando por fazer parte do trabalho explorado e mal remunerado. A capacidade de suportar toda sorte de enxovalho e esculachos é sinal de força e vigor para "vencer na vida". A fantasia da autoexploração faz parte de um esforço por se adequar ao que o sistema pede. Não existe nenhuma garantia de que ser trabalhador impeça que uma população não seja alvo da necropolítica. A fantasia de ser uma "pessoa de bem" - leia-se branca, cisheteronormativa, classe média e sem deficiências é uma aposta de estar salva do espectro neoliberal do necropoder. Partindo das reflexões de Mbembe, interpretamos que o universo neoliberal promove um deslocamento topológico das disputas e de todos os processos de competição capitalista, radicalizando a busca por uma conversão. Os "nascidos escolhidos" apenas mantêm a sua posição, enquanto os que não têm o "direito natural" à salvação, lutam desesperadamente para fazer parte dessa tribo seleta. A medida é o trabalho bem-sucedido, isto é, sucesso. Nessa disputa, considerando as observações marxianas, alguns poucos são donos dos meios de produção, a maioria integra a classe trabaIhadora e alguns fazem um tipo de aventura pequeno burguesa acreditando que podem chegar à terra

\footnotetext{
2 "Realizado em 1989, na capital estadunidense, o encontro de instituições como Fundo Monetário Mundial, Banco Mundial e o Departamento de Tesouro dos Estados Unidos ficou popularmente conhecido como o Consenso de Washington. Por meio da sugestão de várias medidas econômicas, todas voltadas para uma globalização dos mercados, o Consenso de Washington serviu, durante muito tempo, como a base de orientação do funcionamento de várias economias ao redor do mundo." Obs.: Grifos da matéria. Fonte: https://www.suno.com.br/artigos/consenso-de-washington/
} 
Thaumazein, Ano IX, v. 14, n. 27, Santa Maria, p. 81-93, 2021.

prometida da burguesia. Mas, como no Titanic ${ }^{3}$, não existem botes e nem coletes salva-vidas para todo mundo. A maioria não poderá fazer parte da tribo eleita e viverá como um ser humano morto-vivo em busca de uma fantasia irrealizável. Sem fantasia o necropoder não seria viável, enquanto o barco Titanic afundava, os músicos continuaram tocando.

\section{ESCRAVAGISMO, FANTASMAGORIA BRANCA E OS “MORTOS-VIVOS”}

Dentre os fatores que compõe o necropoder, a fantasia é uma delas. Se tomarmos esse conceito em termos psicanalíticos, "toda fantasia é a realização de um desejo, uma correção da realidade insatisfatória" (FREUD, 1996, p. 137). Daí, a fantasia - aqui entendida como um mecanismo para facilitar o nosso acesso ao prazer diante de obstáculos, uma maneira de enfrentar a realidade. O projeto de colonização funciona dentro de uma fantasia de que ser gente com direito à humanidade significa ser uma pessoa branca. Daí, a tese fanoniana de Pele negra, máscaras brancas. Mas, vale dizer, as pessoas brancas também usam "máscaras brancas" que apagam suas humanidades: as fantasias constituintes do racismo que estabelecem ser branco como "uma fantasia da imaginação europeia que o Ocidente se esforçou por naturalizar e universalizar" (MBEMBE, 2018, p. 88). Esta fantasia branca rapidamente colheu inspiração no mito da tribo eleita, num mundo racializado, o "homem branco" se autodesignou como feito à imagem e semelhança de Deus. Na esteira de dispositivos culturais, teológicos, institucionais e econômicos (MBEMBE, 2018, p. 90), a fantasia do branco funciona como uma "constelação de objetos de desejo e marcadores públicos de privilégio" (MBEMBE, 2018, p. 90). A marca ocidental de estar no mundo é a branquitude - aqui entendida, simplesmente, como privilégio branco. O que pode ser traduzido como uma "figuração da brutalidade e da crueldade, de uma forma singular de predação e de uma capacidade inigualada de sujeição e exploração de povos estrangeiros" (MBEMBE, 2018, p. 91). Nesta fusão entre o discurso mítico de um povo eleito advinda do sionismo com o privilégio branco num esquema colonial, capitalista e patriarcal, instalamos um solo mais do que fértil para que os dispositivos do necropoder sejam sólidos.

"Não existe missão negra, não existe fardo branco" (FANON, 2020, p. 232). O risco de sobrecarregar as pessoas negras com a tarefa de tentar "salvar" o mundo do racismo é perigoso demais. O enorme terror da violência sistemática das sociedades imersas na necropolítica decorre de uma base psicológica, as pessoas brancas não assumem seus privilégios e como têm usado essa fantasmagoria ocidental para desumanizar a si e todos os outros grupos humanos. A manutenção domesticada da luta de classes, a crença de que todos podem conquistar o "sucesso" está intimamente ligada à produção de imaginários vinculados à raça e ideologia de que alguns pertencem a um "povo eleito". Esse sucesso que garante a vida é "branco" e completamente estruturado no terreno do capitalismo. Fora do mercado não há espaço para sucesso. A vida passa a valer à medida que podemos trocá-la por produtos e mercadorias. É preciso provar que se pode entrar nos mundos das compras para evitar os mundos de morte.

3 Titanic - Foi um transatlântico de luxo que bateu contra um iceberg em pleno alto-mar sem que houvesse botes salva-vidas para todas as pessoas. Dessa forma, a maioria morreu congelada. A história tem muitos registros e foi contada em um longa-metragem que rendeu altas bilheterias. No filme, há cenas intrigantes, como a da orquestra que continua tocando alheia ao naufrágio. Fonte: https://bbc.in/3AT06Ai. 
Thaumazein, Ano IX, v. 14, n. 27, Santa Maria, p. 81-93, 2021.

[...] "mundos de morte", formas novas e únicas da existência social, nas quais vastas populações são submetidas a condições de vida que lhes conferem o status de "mortos-vivos". O ensaio também esboçou algumas das topografias reprimidas de crueldade (fazenda e colônia, em particular) e sugeriu que, sob o necropoder, as fronteiras entre resistência e suicídio, sacrifício e redenção, martírio e liberdade desaparecem. (MBEMBE, 2015. p. 146).

A metáfora dos "mortos-vivos" é muito relevante. Vale a pena trazer à cena uma sequência de aventuras em História em Quadrinhos criada, em 2003, pelo trio estadunidense Robert Kirkman, Tony Moore (autores) e Charlie Adlard (desenhista/ilustrador) intitulada The Walking Dead, que em 2010 se transformou num seriado de TV desenvolvido por Frank Darabont e sua equipe. Os mortos-vivos podem ser efetivamente assassinados pelas pessoas que estão vivas, numa luta brutal para escapar do contágio de um vírus. Pois bem, essa ficção é uma boa ilustração dos mundos de morte. Qual é a nossa interpretação para essa expressão conceitual apresentada ligeiramente no ensaio? Eis nossa hipótese: trata-se de um fenômeno que recobre mundos fora do mercado neoliberal branco autorizado. Todas as pessoas que estão fora do mercado, habitando determinados territórios que são inspirados nas paisagens coloniais, gente com determinadas características fenotípicas fora daquelas do povo eleito - raça branca, excluídas do mundo produtivo e congêneres transformam-se em mortas-vivas disponíveis como alvo dos vivos. Talvez, seja por isso que algumas pessoas em ascensão social cometam extravagâncias, usando joias em excesso e fazendo questão de mostrar que podem "pagar o preço", isto é, estão vivas. Nos anos 1990, não eram raros videoclipes de artistas pop posando com carrões, relógios caros, cordões de diamantes e esbanjando garrafas de champanhe e bebidas que valiam seu peso triplicado em ouro. Para as populações condenadas previamente à pena de morte, a inserção na lógica do consumo tornou-se o modo de dizer: "Nós estamos vivos!", o que não evita que a necropolítica as atinja.

Como se estabelece essa relação entre mundos de morte e o mercado capitalista? A lógica do mercado se trata de comprar, descartar e comprar novamente. Isso quando falamos de produtos, mas e no caso de pessoas? Um ser humano não é uma peça ou um objeto. No entanto, foi assim que pessoas negras foram tratadas no período escravagista, como coisas que podiam ser repostas. Daí, existe um percurso histórico, desde a produção fabril liberal até o processo neoliberal, que incorpora elementos do escravagismo e organiza um sistema em que, ao invés de rejeitar somente objetos, as pessoas também passam a ser descartáveis.

Sem dúvida a fábrica já conhecia o sistema de prêmios mas a empresa se esforça mais profundamente em impor uma modulação para cada salário, num estado de perpétua metaestabilidade, que passa por desafios, concursos e colóquios extremamente cômicos. Se os jogos de televisão mais idiotas têm tanto sucesso é porque exprimem adequadamente a situação de empresa. (DELEUZE,1996).

À medida que se declara a possibilidade de descartabilidade das pessoas, o ser humano é incluído num mundo de morte. O que não é necessariamente uma novidade, o processo colonial cometeu genocídios e produziu zonas de longo alcance de trabalhos forçados. A tese mbembeana está justamente no caráter inédito do alargamento dessas zonas de morticínio. No contexto necropolítico, os 
mundos de morte têm jogos que colocam a vida em risco para muitos contingentes o tempo todo. A tribo eleita protegida desses mundos diminui sempre. O colóquio agora tem uma regra: "prove que você merece permanecer vivo". Existe uma lógica de compensação. Por exemplo, se você era um palestino morando na Faixa de Gaza durante os conflitos entre o Estado de Israel e o Grupo Hamas - considerando o exemplo mbembeano - seria preciso provar mil vezes que você merecia viver. Uma pessoa negra abordada pela Polícia, num estabelecimento comercial ou mesmo nas ruas, seja adulta ou criança no Brasil ou Estados Unidos pode ter o mesmo destino de Amarildo ${ }^{4}$, Cláudia Silva $^{5}$, João Pedro ${ }^{6}$, George Floyd ${ }^{7}$, as primas Emily Victoria e Rebeca Beatriz ${ }^{8}$, os meninos de Belford Roxo $^{9}$ entre inúmeros casos. O que essas pessoas precisariam fazer para provar o direito à vida? Talvez, tendo fama e/ou dinheiro, como Derek Chauvin, um rapper famoso que foi liberado ao ser reconhecido por um policial numa abordagem de rotina. Os mundos de morte são móveis, não são somente territórios conflagrados em que as forças policiais entravam atirando nos anos 2000 no Estado do Rio de Janeiro.

No final da segunda década do século XXI, com a emergência de uma pandemia mundial, todas as pessoas passaram a ter o "direito de matar", os mundos de morte se ampliaram largamente. Em 17 de abril de 2020, Achille Mbembe publicou o artigo Direito universal à respiração. Mbembe aponta que agora todos podem matar, todo mundo poderia ser uma máquina de produção de morte desde que contraísse e transmitisse o vírus. O monopólio de matar não é uma regra neoliberal. Se a Palestina é o exemplo do necropoder, o raciocínio lógico informa que o Estado de Israel é uma máquina muito elaborada de produzir mundos de morte. Mas, além de Estados atuando em Israel, EUA e no Brasil através das forças oficiais de segurança pública, nós encontramos milícias armadas no Brasil que colocam "ordem" em territórios da classe popular, homens com crise de masculinidade patriarcal (tóxica) fazendo ataques em massa nos Estados Unidos da América, dentre outras máquinas de morte. O tratamento dado pelo atual governo brasileiro à pandemia da Covid-19 a fim de popularizar o vírus, numa ineficaz "imunização de rebanho"10 tornou 4 Amarildo de Souza desapareceu em 2013, na Rocinha. A Justiça concluiu que Amarildo foi torturado até a morte. O corpo dele não foi encontrado até hoje. Em 2016, 13 policiais militares foram condenados por tortura seguida de morte, ocultação de cadáver e fraude processual. Fonte: https://glo.bo/3hKgKcu

5 Cláudia Silva Ferreira, que teve o corpo arrastado por 350 metros em Madureira (RJ) por um carro da Polícia Militar e foi morta por um dos disparos pelos quais foi atingida. Fonte: https://glo.bo/3wtX162

6 João foi morto durante uma operação das polícias Civil e Federal. Ele foi atingido na barriga e levado para um helicóptero, tendo ficado 17 horas desaparecido até ser declarado morto. Fonte: https://bit.ly/3e04Qdr

7 George Floyd, 43 anos morreu em 2020 após ter o pescoço pressionado pelo joelho do policial Derek Chauvin, em Mineápolis, por 9 minutos e 29 segundos. Fonte: https://glo.bo/36ncZ7z

8 Emily Victória Silva dos Santos, de 4 anos, e Rebeca Beatriz Rodrigues dos Santos, de 7 anos morreram baleadas após um tiroteio em Duque de Caxias, no Rio de janeiro. Apesar de uma moradora dizer que os projéteis partiram de policiais, a PM (Polícia Militar) do Estado afirma que não disparou nenhum tiro na operação. Fonte: https://bit.ly/3wpY6rW.

9 Lucas Mateus, Alexandre e Fernando Henrique Meninos sumiram no dia 27 de dezembro de 2020 em Belford Roxo, Baixada Fluminense. Até o momento, suas famílias estão sem resposta sobre os três meninos desaparecidos de Belford Roxo. Fonte: https://bit.ly/3jYILAQ. Obs.: Todas as pessoas destas notas são negras.

10 "Também conhecida como imunidade coletiva, ela se vale de um cálculo utilizado por epidemiologistas e infectologistas para determinar a porcentagem de uma população que precisa receber as doses de uma de uma vacina para que todos os indivíduos fiquem protegidos de um vírus ou bactéria - mesmo aqueles que não foram imunizados por algum motivo. 
possível que uma pessoa assintomática pudesse transmitir e matar, promovendo nada mais que uma expressão do necropoder.

\title{
CONSIDERAÇÕES PARCIAIS: COMO RESISTIR AO NECROPODER?
}

A pergunta é: diante de mundos de morte por todos os lados, como resistir ao necropoder? Em certa medida, Mbembe nos provoca de modo agudo diante de uma crise crônica. O que o filósofo propõe é uma inflexão radical sobre um fenômeno que parece ganhar cada vez mais força em franca expansão: o necropoder pode ser contido? Existiriam possibilidades de resistir a ele? Enfrentá-lo? Algumas pistas estão No sair da grande noite e num pequeno ensaio intitulado Afropolitanismo.

O necropoder precisa de fronteiras, sejam elas geográficas, raciais, de gênero, de classe ou de qualquer ordem. Porque sem estabelecer pontos fixos e uma terra prometida, as tecnologias necropolíticas não são possíveis. A circulação livre sem fronteiras, o movimento contínuo de dispersão e imersão, o viver nômade é estranho à ideia de uma terra prometida e, portanto, de uma tribo eleita com direito a fixar-se.

\begin{abstract}
Visto a partir da África, o fenômeno da circulação dos mundos possui ao menos duas faces: aquela da dispersão, que acabo de evocar, e aquela da imersão. Historicamente, a dispersão das populações e das culturas não foi somente o fenômeno de vinda de estrangeiros para se instalar em nossa casa. Na verdade, a história pré-colonial das sociedades africanas foi, de ponta a ponta, uma história de povos, incessantemente, em movimento através do conjunto do continente. Trata-se de uma história de culturas em colisão, tomadas pelo turbilhão das guerras, das invasões, das migrações, dos casamentos mistos, de religiões diversas que são apropriadas, de técnicas que são trocadas e de mercadorias que são vendidas. A história cultural do continente praticamente não pode ser compreendida fora do paradigma da itinerância, da mobilidade e do deslocamento.

Aliás, é essa cultura da mobilidade que a colonização procura, em sua época, fixar através da instituição moderna da fronteira. Rememorar essa história da itinerância e das mobilidades é a mesma coisa que falar das misturas, dos amálgamas, das superposições. Contra os fundamentalistas do "costume" e da "autoctonia". (MBEMBE, 2015, p 69).
\end{abstract}

Pois bem, a itinerância e o fim das fronteiras, uma celebração constante de um mundo sem estrangeiridade é uma alternativa de enfrentamento ao necropoder. É preciso que as fronteiras e muralhas deixem de existir. A Palestina e o Estado de Israel precisam deixar de constituir territórios em disputa. Uma favela carioca da zona sul da cidade do Rio de Janeiro precisa deixar de ser uma intervenção estética da pobreza na paisagem de um bairro de classe média alta. O modo de resistir ao necropoder está

Esse número varia bastante de acordo com as bastante de acordo com as características da doença. [...]

Ao falarmos do atual coronavírus, a situação fica um pouco mais complicada. Isso porque não temos nenhuma vacina ou remédio disponível. Portanto, para alcançar uma eventual imunidade de rebanho nesse cenário, seria preciso pedir às pessoas que saiam de casa e se exponham ao vírus no dia a dia. [...]

Existem projeções dizendo que $43 \%$ da população teria que se infectar com o vírus para atingir a imunidade de rebanho tem estudo falando em $20 \%$, outros em $80 \%$. [...]

Numa conta de padaria, 86 milhões de brasileiros teriam a Covid-19. Quais as consequências? De acordo com as evidências mais recentes, algo em torno de 17 milhões de internações em hospitais e 860 mil mortes". Fonte: https://bit.ly/3dXeyNL 
na lição histórica afropolitana que faz de todos os humanos eternos itinerantes. É a itinerância, o caráter nômade da vida que pode acabar com os mundos de morte; sobre os seus dispositivos, os seus usos e formas de expressão trataremos com mais vagar em outra oportunidade. Cabe dizer, contra o necropoder só cabe a itinerância cosmofílica que não busca uma terra prometida, mas encontros que gerem novos mundos, interações inesperadas e conflitos que se resolvem com mais acolhimento e mais intimidade. A hipótese de enfrentamento ao necropoder pode ser dita como: à medida que a etapa neoliberal do capitalismo segue radicalizando os conflitos de classe, ampliando o fetiche da mercadoria para todas as instâncias da vida. Um novo Éden é criado praticamente inacessível, ao seu redor uma muralha, uma porta estreita pela qual somente gente escolhida pode entrar. O necropoder se instala com um alcance fulminante para toda gente que está fora da Terra prometida. Daí, combatê-lo se dá por uma ruptura com a lógica de mercado, com uma recusa radical do capitalismo em suas formas mais sofisticadas de transformar gente em mercadoria. A itinerância que aumenta as oportunidades de intimidade e acolhimento é antinecropolítica, à medida que ela não precifica o mundo da vida. Ora, se a precificação do mundo da vida é justamente a produção de mundos de morte, a nossa alternativa está em desprecificar a vida. O que só é viável enfrentando o capitalismo, abrindo as cancelas do mercado, reestabelecendo a circulação das coisas como um fluxo vital de sangue que oxigena um corpo.

\section{REFERÊNCIAS}

DELEUZE, Gilles. Post-scriptum sobre as sociedades de controle, p. 219; In: DELEUZE, G. Conversações, Conversações, 1972 -1990. PELBART, Peter Pál (Trad.). Rio de Janeiro: Editora 34, 1996.

INTERNATIONAL MILITARY TRIBUNAL AT NUREMBERG. Nuremberg Code. In: Trials of War Criminals before the Nuremberg Military Tribunals under Control Council Law n. 10, v. 2, p. 181-182. Nuremberg: Washington, DC: US Government Printing Office, 1949.

FANON, Frantz. Os condenados da terra. ROCHA, Elnice Albergaria e MAGALHÃES, Lucy (Trad.). Juiz de Fora: Editora UFJF, 2005.

FREUD, Sigmund. A psicopatologia da vida cotidiana. In: Sigmund Freud. Obras psicológicas completas de Sigmund Freud. SALOMÃO, Jayme (Trad.). Rio de Janeiro: Imago, 1996.

KAUFMANN, Yehezkel. A religião de Israel: do início ao exílio babilônico. CANCIAN, Attílio (Trad.). São Paulo: Perspectiva, 1989.

LISSOVSKY, Alexandre. 2000 anos depois: o renascimento de Israel. Herzl e o sionismo político. Rio de Janeiro: Centro Edelstein de Pesquisas Sociais, 2009, p. 49-94. Disponível em: https://bit.ly/36kS4Sr. Acesso: 13 maio 2021.

MBEMBE, Achille. Afropolitanismo. SILVA, Cleber Daniel Lambert (Trad.). Áskesis. v. 4, n. 2, jul./dez. 2015, p. 68-71. 
MBEMBE, Achille. Crítica da razão negra. NASCIMENTO, Sebastião (Trad.). N. ${ }^{0} 1$ edições, 2018.

MBEMBE, Achille. Direito universal à respiração. Instituto Humanas Unisinos. Disponível em: https:// bit.ly/2Uw06W3. Acesso: 13 maio 2021.

MBEMBE, Achille. Necropolítica. Arte \& Ensaios (Revista). n. 32. UFRJ, dez. 2015.

NOTERMANS, Ton. Money, markets, and the State: social democratic economic policies since 1918. Cambridge: Cambridge University. 2000.

OLIVEIRA, Augusto Neftali Corte de. Neoliberalismo durável: o Consenso de Washington na Onda Rosa Latino-Americana. In: Opinião Pública. Campinas, v. 26, n. 1, jan.-abr., 2020, p. 158-192.

RODRIK, Dani. Goodbye Washington Consensus, Hello Washington Confusion? Journal of Economic Literature, v. 44, n. 4, p. 973-987, 2006.

SAND, Shlomo. A invenção da terra de Israel: da terra santa à terra prometida. Tradução Lucia Brito. São Paulo: Benvirá, 2014.

SORJ, Bernardo. Geopolítica e cultura: a trajetória de Israel. In: História (São Paulo). v. 33, n. 2, p. 57-71, jul./dez. 2014.

ZANINI, Fábio. Alemanha admitirá o genocídio africano anterior ao fascismo. Folha de São Paulo, Mundo. Maio/2021. São Paulo.

\section{JORNAIS E REVISTAS}

BBC. Naufrágio do Titanic: busca por telégrafo abre batalha judicial sobre descanso dos mortos. BBC Brasil. Brasil. Out/2020. Disponível em: https://bbc.in/3AT06Ai. Acesso: 13 maio 2021.

BETIM, FELIPE. Mais de 100 dias sem resposta sobre os três meninos desaparecidos de Belford Roxo. El País. São Paulo. Abr/2021. Violência contra criança. Disponível em: https://bit.ly/3qXpaBr. Acesso: 13 maio 2021.

BIERNATH, André. O que significa a tal da imunidade de rebanho?. Veja Saúde. Medicina Ago./ 2020. Disponível em: https://bit.ly/3jYNeCo. Acesso: 13 maio 2021.

G1. Arrastada por carro da PM do Rio foi morta por tiro, diz atestado de óbito. G1. Rio de Janeiro. Mar. 2014. Disponível em: https://glo.bo/3jYCMeo. Acesso: 13 maio 2021.

G1. Homenagens marcam 1 ano da morte de George Floyd nos EUA. G1. maio/2021. Disponível em: https://glo.bo/3hsvw80. Acesso: 25 maio 2021.

RECORD TV RIO. Emily, de 4 anos, e Rebeca, de 7, são mortas em tiroteio no Rio. Record TV Rio. Rio de Janeiro. Dez./ 2020. Disponível em: https://bit.ly/3k1wDOq. Acesso: 13 maio 2021. 
REIS, Tiago.Consenso de Washington: entenda o que foi esse conjunto de medidas liberais. Suno Artigos. Economia. Fev./ 2019. Disponível em: https://bit.ly/3yBBKsL. Acesso: 13 maio 2021.

RESENDE, Leandro. Caso João Pedro, morto em ação policial no RJ, tem reconstituição marcada. CNN Brasil. Out./ 2020. Disponível em: https://bit.ly/3jSJeUa. Acesso: 13 maio 2021.

SCHMIDT, Larissa e GIMENEZ, Elza. Major condenado por tortura e morte do pedreiro Amarildo é reintegrado à Polícia Militar. G1. Rio de Janeiro. Fev./2021. Disponível em: https://glo.bo/2TQTotF. Acesso: 13 maio 2021. 